\title{
Editorial for the special issue on photosynthesis and hydrogen energy research for sustainability-2019
}

\author{
Suleyman I. Allakhverdiev ${ }^{1}$
}

Published online: 11 June 2020

(c) Springer Nature B.V. 2020

Oxygenic photosynthesis supports life on our planet by providing organic substrates through the process of converting solar energy to the energy of chemical bonds. The oxygen is released as a by-product due to water photo-oxidation making the diversity of aerobic life possible. Photosynthesis supplies organic compounds as an energy source, maintains oxygen and carbon dioxide level in the atmosphere. It made the accumulation of fossil fuels possible. Nevertheless, in the nearest future the mankind is going to face two essential challenges - the growing energy demand and succeeding environmental problems. But photosynthesis can give us the clue to cope with the lack of energy supply and to reduce the emission of greenhouse gases by artificial energy generation mimicking natural process. Therefore, studies of photosynthesis mechanism are of current interest to the present day. The accumulated knowledge on photosynthetic pathways can contribute to the development of bioenergetics area in order to fulfill the needs of mankind.

However, there are still many questions concerning photochemical reactions and the photosynthetic apparatus of various organisms that are needed to be solved. In order to give the opportunity to scientists from all over the world to meet and discuss their findings in the field of photosynthesis and hydrogen energy. There is, of course, the most prestigious triannual "International Congress of Photosynthesis Research", organized by the International Society of Photosynthesis Research (ISPR), which, we all support and participate in.

At the Brisbane congress on Photosynthesis (12th Congress of ISPR) in 2001, based on our personal discussion with Robert Carpentier (chairperson of 13th Congress of ISPR in Montreal, in 2004), Gyozo Garab, Prasanna Mohanty, Slava Klimov and author of this text we felt and

Suleyman I. Allakhverdiev

suleyman.allakhverdiev@gmail.com

1 K.A. Timiryazev Institute of Plant Physiology, RAS, Moscow, Russia came to the conclusion that we need another, smaller and more focused conference. Robert Carpentier asked me to take responsibility and to organize the new conference. After that, for this purpose, another International Conference on "Photosynthesis and Hydrogen Energy Research for Sustainability" was established and from that time, up to now, I am the main organizer and main coordinator of it. (Our next, 11 th International Conference will be held in Bulgaria in 2021; for more info, please visit at https://icprs.ru/).

The first conference took place in Trois-Rivières, Quebec, Canada in 2004, with Robert Carpentier being a chairman. The meeting titled was "Photosynthesis and the postgenomic era: from biophysics to molecular biology, a path in the research of photosystem II" was held in honoring of Professor Norio Murata, a renowned scientist who has made significant contributions in the field of photosynthesis, lipid research, and molecular biology of stress perception and response. The conference was aimed at reviewing the achievements in research on Photosystem II and welcomed 200 participants originating from more than 30 countries (Carpentier and Allakhverdiev 2005).

Ever since the meeting became popular in scientific society. Next conference occurred in Pushchino, Russia in 2006 and was called "Photosynthesis in the post genomic era: structure and function of photosystems". It was dedicated to honoring of Professor James Barber a renowned scientist who has made an outstanding contribution to the understanding of photosystem II through the structural studies. The conference covered both the review on current status of photosynthesis research and discussion of its future directions. Nearly 300 scientists from 38 countries were participated in the conference (Allakhverdiev et al. 2007; Allakhverdiev 2008).

Later, after a 5-year break the tradition of Photosynthesis Research meeting was renewed. The next conference "Photosynthesis research for sustainability" was held in Baku, Azerbaijan, in 2011. Nearly 280 participants from 41 countries were welcomed to take part in this meeting. The 
conference consisted of topics on the important aspects of photosynthesis with relation to global challenges. For the first time the hydrogen energy and artificial photosynthesis field was included to the program. At this conference, nine young scientists among Ph.D. students and post-docs who had done outstanding research in photosynthesis field were awarded with special prizes (Allakhverdiev et al. 2011).

Two years later Baku welcomed the conference participants again. "Photosynthesis and Hydrogen Energy Research for Sustainability-2013" was held in honor of Professor Jalal A. Aliyev who has made a significant contribution to the study of the theoretical bases of photosynthetic productivity of agricultural plants, especially wheat plants. This conference was noticeable with the invited speakers. Among them, a Nobel prize winner in chemistry John E. Walker (the UK) delivered a lecture about the ATP synthesis (Allakhverdiev et al. 2013).

Photosynthesis research conference since then became almost annual and took place in Pushchino, Russia, several times. Institute of Basic Biological Problems, Russian Academy of Sciences, welcomed the participants from all over the world in 2014 (in honor of Vladimir A. Shuvalov). Vladimir Shuvalov is an honored scientist who has made outstanding contribution to the basic principles of charge transfer processes in the reaction centers of both plants and photosynthetic bacteria.

Photosynthesis Research meeting attracts attention of international scientific community, and different institutions are chosen by the organizers to be the conference venue. Thus, in 2015 the conference took place in Conference Center of the Orthodox Academy of Crete, Greece. It was made to honor George C. Papageorgiou, renowned scientist, a founding member and an Executive Board member of the Hellenic Biochemical and Biophysical Society, a member of the American Chemical Society, the American Biophysical Society, and the European Expert Committee on UNESCO, the representative of Greece deputed to the Advanced Studies Institutes program of NATO, and a member of the Editorial Board of Photosynthetica journal. His research interests centered on the theme of chlorophyll fluorescence. G.C. Papageorgiou made major contribution to the mechanism of regulation of energy dissipation and preceding changes in the thylakoid membrane structure. Also, his interest is related to the biotechnological usage of photosynthesis for sustained production of reducing power and hydrogen (Allakhverdiev et al. 2016).

Next Meeting in honoring of Nathan Nelson and Turhan Nejat Veziroglu held in Pushhcino (Allakhverdiev et al. 2016). Nathan Nelson is an awarded scientist who has worked in many aspects of photosynthesis including membrane proteins and membrane protein complexes, V-ATPase, neurotransmitter transporters, metal-ion transporters. The major contribution of his work is solving the crystal structure of plant PSI. Nejat Veziroglu is an honorable researcher in hydrogen energy field and the founding editor of the International Journal of Hydrogen Energy. He is a president of the International Association for Hydrogen Energy, initiator of the World Hydrogen Energy Conference and the World Hydrogen Technology Convention. The program of the conference covered basic and applied aspects of photosynthesis research. The second half of the meeting was dedicated to biohydrogen. Among the participants, there was a Nobel Prize winner in chemistry Ada Yonath and many other honorable researches in the field of photosynthesis research and hydrogen energy. There was also the ceremony for young scientist awards, that became a good tradition on the conference.

In 2017 the conference was held in School of Life Sciences, University of Hyderabad, Hyderabad, India. The conference had honored three international scientists William Cramer, Govindjee, and Agepati S. Raghavendra, renowned scientists in the field of photosynthesis (Allakhverdiev et al. 2017). William Cramer contributed significantly on structure and function of membrane proteins involved in photosynthetic electron transport and energy transduction; cytochrome complexes; ion channels, cellular import, colicins, receptor function. Govindjee major research areas are Primary Photophysics and Photochemistry of Oxygenic Photosynthesis, Unique Role of Bicarbonate on the Electron Acceptor Side of Photosystem II and significantly wrote History and Biography: Tributes and News Reports to the photosynthesis community. The thrust of Agepati S. Raghavendra's research has been on photosynthetic carbon metabolism and its interactions with mitochondrial respiration and nitrogen metabolism. His group has also contributed significantly to the topic of bioenergetics and signaling components of guard cells in relation to stomatal function. The speakers at the conference are the world leaders in the field of bioenergy. As many as 350 participants have come together from 25 countries. In this conference the young talented graduate and postdoctoral fellows were introduced to give a oral talks. As a tradition students were given best poster and awards.

In 2018, this conference was held again in Baku, but this time, it was a memorial to Jalal Aliyev, who passed away in 2016 (see Huseynova et al. 2016).

The later Photosynthesis and Hydrogen Energy Research for Sustainability conference occurred in 2019, in a beautiful location of Beloselsky-Belozersky Palace, Saint Petersburg, Russia. The conference honored the research of Tingyun Kuang, Anthony Larkum, Cesare Marchetti, and Kimiyuki Satoh. There were two parallel research sessions: Photosynthesis Research for Sustainability devoted to studies of the photosynthetic apparatus, and Hydrogen Energy Research for Sustainability devoted to research on biohydrogen and fuel cell production. Both sessions included fundamental 
and applied aspects of research and work on artificial photosynthesis by using nanomaterials and nanotechnology (Borisova-Mubarakshina et al. 2019, 2020).

This special issue of the PRES contains a selection of the best 27 papers from the last Meeting in Saint Petersburg (Russia), that honored of Tingyun Kuang, Anthony Larkum, Cesare Marchetti, and Kimiyuki Satoh.

Acknowledgements A big thank to all the authors of the manuscripts of this issue. Also, we all very thankful to Terry Bricker (Editor-inChief) for giving us this opportunity, and to Carola Vermeeren for her invaluable support.

\section{References}

Allakhverdiev SI (2008) Resent perspectives of photosystem II: structure, function and dynamics. Photosynth Res 98:1-5

Allakhverdiev SI, Shuvalov VA, Klimov VV (2007) Structure and function of photosystems. Biochim Biophys Acta 1767:401-403

Allakhverdiev SI, Huseynova IM, Govindjee G (2011) In: International conference on photosynthesis research for sustainability-2011, July 24-30, 2011, Baku, Azerbaijan. Photosynth Res. 110:205-212

Allakhverdiev SI, Huseynova IM, Govindjee G (2013) In: International conference on Photosynthesis research for sustainability-2013: In honor of Jalal A. Aliyev, held during June 5-9, 2013, Baku, Azerbaijan. Photosynth Res 118:297-307

Allakhverdiev SI, Tomo T, Govindjee G (2014) International conference on 'photosynthesis research for sustainability-2014: in honor of Vladimir A. Shuvalov, held on June 2-7, 2014, in Pushchino, Russia. Photosynth Res 122:337-347

Allakhverdiev SI, Tomo T, Stamatakis K, Govindjee G (2016) In: International conference on photosynthesis research for sustainability-2015 in honor of George C. Papageorgiou, September 21-26, 2015, Crete Greece. Photosynth Res 130:1-10

Allakhverdiev SI, Subramanyam R, Tomo T (2019) International conference on Photosynthesis and Hydrogen Energy Research for Sustainability-2017. Photosynth Res 139:1-8

Borisova-Mubarakshina MM, Tsygankov AA, Tomo T, Allakhverdiev SI, Eaton-Rye JJ, Govindjee G (2019) The 10th international conference on photosynthesis and hydrogen energy research for sustainability: a pictorial report in honor of Tingyun Kuang, Anthony Larkum, Cesare Marchetti and Kimiyuki Satoh. Int J Hydrogen Energy 44:30927-30934

Borisova-Mubarakshina MM, Tsygankov AA, Tomo T, Allakhverdiev SI, Eaton-Rye JJ, Govindjee G (2020) In: International conference on photosynthesis and hydrogen energy research for sustainability-2019: in honor of Tingyun Kuang, Anthony Larkum, Cesare Marchetti, and Kimiyuki Satoh. Photosynth Res https:// doi.org/10.1007/s11120-019-00687-w

Carpentier R, Allakhverdiev SI (2005) Foreword. Photosynth Res 84:v-vi

Huseynova IM, Allakhverdiev SI, Govindjee G (2016) Jalal A. Aliyev (1928-2016): a great scientist, a great teacher and a great human being. Photosynth Res 128:219-222

Publisher's Note Springer Nature remains neutral with regard to jurisdictional claims in published maps and institutional affiliations. 